\title{
Correction to: Complete functional recovery in a child after endovascular treatment of basilar artery occlusion caused by spontaneous dissection: a case report
}

\author{
Ljubisa Borota $^{1} \cdot$ Sylwia Libard ${ }^{2} \cdot$ Markus Fahlström $^{1} \cdot$ Francesco Latini $^{3} \cdot$ Erik Lundström $^{4}$ \\ Published online: 11 January 2022 \\ ๑) Springer-Verlag GmbH Germany, part of Springer Nature 2022
}

\section{Child's Nervous System \\ https://doi.org/10.1007/s00381-021-05428-w}

In this article the author name "Sylwia Libard" was incorrectly written as "Sylvia Libard".

The original article has been corrected.

Publisher's Note Springer Nature remains neutral with regard to jurisdictional claims in published maps and institutional affiliations.

The original article can be found online at https://doi.org/10.1007/ s00381-021-05428-w.

Ljubisa Borota

ljubisa.borota@akademiska.se

1 Department of Surgical Sciences, Radiology, Uppsala University, Uppsala, Sweden

2 Department of Pathology, Uppsala University, Uppsala, Sweden

3 Department of Neuroscience, Neurosurgery, Uppsala University, Uppsala, Sweden

4 Department of Neuroscience, Neurology, Uppsala University, Uppsala, Sweden 